\title{
Performance improvement of PV panel using water cooling technology under Egyptian conditions
}

\author{
A. Khalil, Mohamed Abdelgaied, Muhammad Hamdy \\ Mechanical Power Engineering Department, Faculty of Engineering, Tanta University, Egypt \\ E-mail; m.hamdy2021@yahoo.com
}

\begin{abstract}
This paper presented the effect of water cooling technique on the performance of PV panels under Egyptian condition. In this study three different positions of the cooling technique was studied (front side, backside and both sides simultaneously). The results of this study was compared to the conventional PV model without cooling to obtain the optimal technology of cooling system. The performance of the system was studied experimentally during the period $10.00 \mathrm{AM}$ : 2.00PM. The experimental results show that the effective power produced for the $P V$ panel increased by $15.5 \%$ (effective $10.0 \%$ ), $13.97 \%$ (effective $8.4 \%$ ) and $17.4 \%$ (effective $11.9 \%$ ) in case of front side, back side and both sides simultaneously cooling technique respectively in comparison with the noncooled panel. Furthermore, it was also possible to decrease panel temperature from an average $55{ }^{\circ} \mathrm{C}$ (non-cooled $\mathrm{PV}$ panel) to $27{ }^{\circ} \mathrm{C}, 32{ }^{\circ} \mathrm{C}$ and $24{ }^{\circ} \mathrm{C}$ in the case of front side, backside and simultaneous front and backside PV panel cooling respectively.
\end{abstract}

Keywords: PV panel, Water spray cooling techniques, Power output, Electrical effeciency.

\section{INTRODUCTION}

Photovoltaic (PV) technology is widely used today in different applications [1-3] but due to relatively high initial investments and low overall efficiency, the number of installed capacities is lower than expected. The second major problem of the commercial PV technology is its cleaning issue, i.e. dust impact and other particles accumulated on the front PV panel surface that can significantly reduce the amount of delivered electricity (in some cases reduction can go up to $30 \%$ ).

Even though novel PV technologies are currently under research and more efficient $\mathrm{PV}$ technologies are bound to be discovered, their expected market price will probably be too high for current market capabilities.

It is well known that electrical efficiency in PV systems can be improved if panel temperature is reduced. This problem has been thoroughly studied in past years through the development of different cooling techniques. For the current market available PV technologies, electrical efficiency degradation is due to the rise of panel temperature which ranges from $0.25 \% /{ }^{\circ} \mathrm{C}$ up to $0.5 \% /{ }^{\circ} \mathrm{C}$ (depending from the specific PV technology used), so possible electrical efficiency improvement can be obtained with a proper cooling technique and keeping in mind that each cooling technique should have proven feasibility.

The objective of this paper was to develop an experimental setup and to investigate a water spray cooling technique, implemented on the front side, backside and simultaneously on the front and back side of a PV panel. The proposed water spray cooling technique can potentially increase PV panel performance due to an evaporation and self-cleaning effect, which is also a great benefit in terms of improved feasibility in the long run.

The previous research work focused on different designs and experimental validation in cooling strategies for PV panels, to investigate their influence on overall efficiency and also to investigate specific energy losses in PV systems [4, 5]. In the majority of the proposed cooling techniques, water was used as a coolant and cooling was implemented on the front or backside of the PV panel. For example, in [6] authors investigated the effect of evaporative cooling implemented on PV panels and the maximal detected total increase in power output was around 19\%. Direct PV panel cooling with an established water flow over the front side of the panel was investigated in [7] and it was possible to increase power output by $9.5 \%$. Furthermore, in [8] authors investigated a water spray cooling technique implemented just on the front side of the PV panel and significant improvement of electrical efficiency was established. A back surface water cooling method was investigated in [9] for hot climate conditions and it recorded an increase in electrical efficiency by around $9 \%$. In addition, alternative cooling techniques that include water as a coolant were studied in $[10,11]$, where the average achieved increase in power output ranged from $10 \%$ to $20 \%$, depending from the specific implemented cooling technique.

In the previously mentioned studies where air was used as a coolant, the achieved PV panel power output was less in magnitude comparing to cases where water was used as a coolant. The water submerging method $[12,13]$ turned out to be one of the most efficient cooling methods as heat rejection magnitude from the PV panel was the highest in comparison to other investigated cooling techniques. Conventional PV panel electrical efficiency can be increased by over $20 \%$ when implementing the water submerging method. However, the key issue regarding the water submerging method is its final technical suitability (i.e. a potential problem for its wide commercial applicability) and there is also an ecological aspect that should be taken into account. A global photovoltaic energy output analysis enhanced by phase change material cooling (PCM) was obtained in [14] and it is found that PCM cooling is not a currently viable option for single-junction.

\section{EXPERIMENTAL SETUP}

\section{A. System configuration}

According to Fig. 1, an experimental setup consists of a flat PV polycrystalline module of $130 \mathrm{~W}$ nominal maximal 
power with an effective surface of $1.0 \mathrm{~m} 2$. The examined panel's general characteristic is specified in Table 1. The panel was equipped with a system of nozzles mounted on the PV panel front side and backside to ensure proper water spray distribution on both sides of the PV panel. The panel was fixed under a specific angle of $30^{\circ}$ (to obtain the highest electricity output), and mounted on a terrace of the Faculty building.

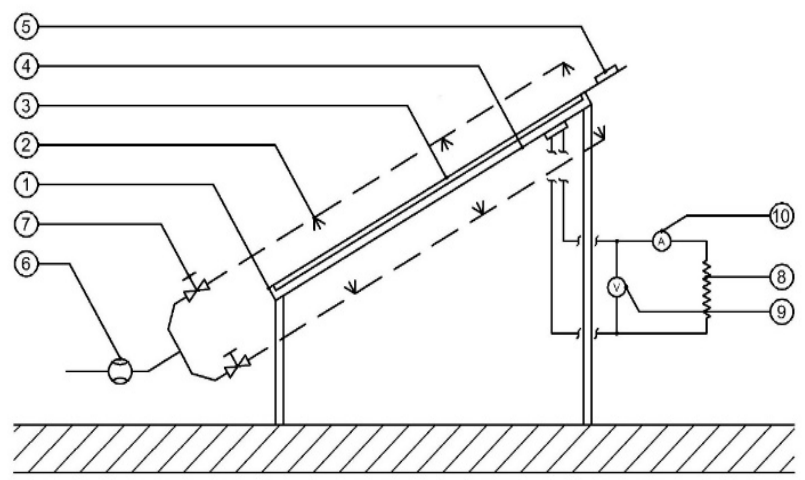

\section{Legend:}

1- Photovoltaic panel.

2- Nozzles

3- Temperature sensor. (Front)

4- Temperature sensor. (Back)

5- Pyranometer.

6- Water flow meter.

7- Water flow regulating valve.

8- Electrical load.

9- Voltmeter.

10- Ammeter.

Figure 1. Schematic layout of the specific experimental setup.

TABLE 1

GENERAL CHARACTERISTICS OF THE EXAMINED PV PANEL AT $1000 \mathrm{~W} / \mathrm{M} 2$ AND $25^{\circ} \mathrm{C}$.

\begin{tabular}{|ll|}
\hline Technical characteristics & \\
\hline Model & PT-130P \\
Module application & Class A \\
Maximal power output & $130 \mathrm{~W} \pm 3 \%$ \\
Maximal voltage/open circuit voltage & $18.15 \mathrm{~V} / 21.53 \mathrm{~V}$ \\
Maximal current/short circuit current & $7.15 \mathrm{~A} / 7.80 \mathrm{~A}$ \\
Effective panel area & $1.00 \mathrm{~m} 2$ \\
\hline
\end{tabular}

The whole system was connected to an I-V (currentvoltage) tracker with a variable electrical load so it was possible to determine specific PV panel power-voltage characteristics during the experimental measurements. Electrical load was set to twenty six different values ranging from 5 watts to 35 watts, voltage and current were measured for each setting by using voltmeter and ammeter.

The system was also additionally equipped with measuring equipment (sensors) to measure a solar irradiation (a pyranometer, HAENNI model Solar 130, was installed on the PV module), panel temperatures (temperature sensors were installed on the front side and backside of the panel), surrounding air temperature, the cooling water (water spray) temperature and finally the cooling water flow (a flow meter was installed on the water flow pipe line).

As it was previously mentioned, water distribution was enabled through 12 fixed nozzles (six nozzles were fixed on the front side of the panel and the same number of nozzles were installed on the backside of the panel), with a wire frame on the front side and backside of the panel, Fig. 2. Water was ensured from a pipeline with an average water flow of $225 \mathrm{l} / \mathrm{h}$.
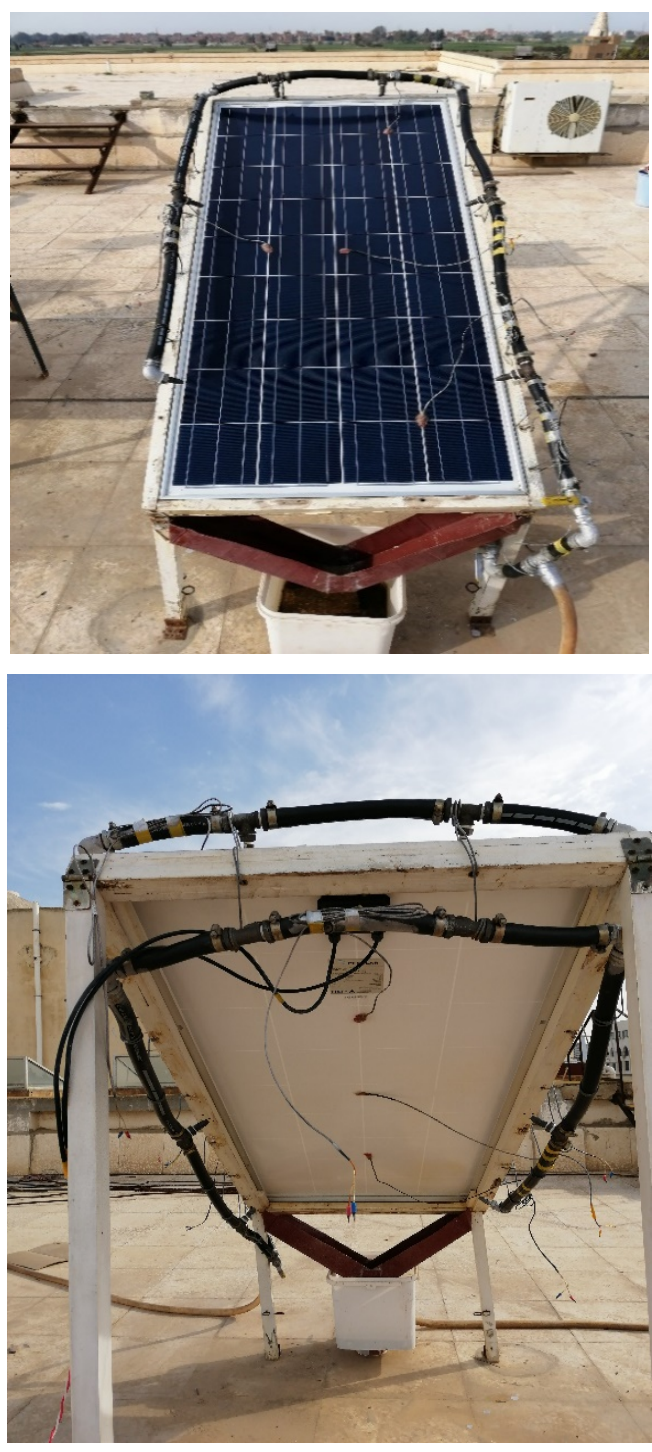

Figure 2. The front and backside of the PV panel with the specific water nozzle system.

Specific nozzle position on the front side of the tested PV panel is shown in Fig. 3 and on the backside in Fig. 4. The nozzles were fixed at an angle of $40^{\circ}$ on the front and back sides of the panel to ensure a wider water spray dispersion over the PV panel as much as possible) and we did not analyze the nozzle angle influence on the panel performance. A water distribution system was ensured through plastic flexible tubes (15 $\mathrm{mm}$ in diameter) on which the nozzles were fixed and mounted on the wire frame.

The distance between the panel surface and nozzles was $100 \mathrm{~mm}$ for the backside of the panel and $150 \mathrm{~mm}$ for the front side of the panel (the previously specified distance was chosen to ensure wider water spray dispersion on the front side and backside of the PV panel). 


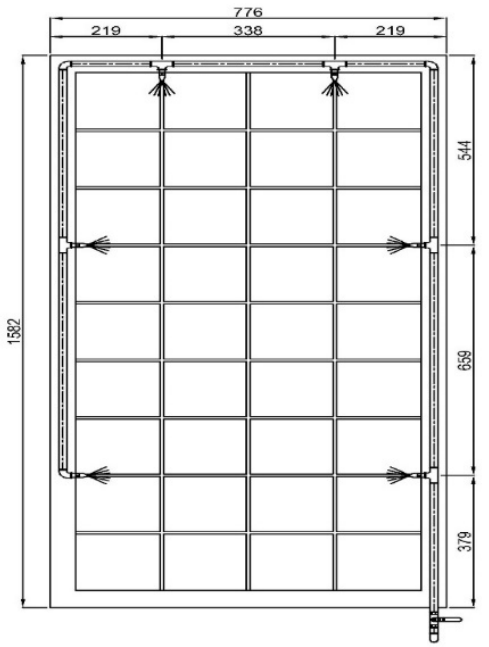

Figure 3. Scheme of the specific nozzle position on the front side of the panel.

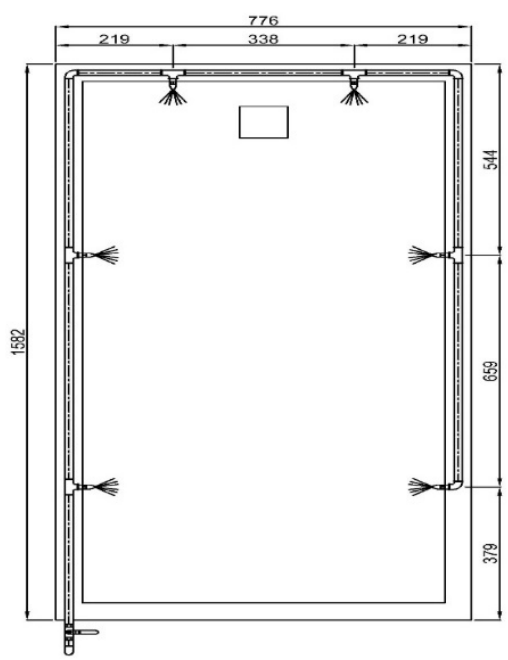

Figure 4. Scheme of the specific nozzle position on the backside of the panel.

Regulating valves were installed to regulate water spray flow separately for the front and backside of the PV panel (so it was possible to just examine the option of the front side or the backside cooling effect for the PV panel).

In general, a water spray cooling technique is more efficient than other already analyzed cooling techniques. The exception is the water submersion method where a higher increase in PV panel efficiency can be obtained (the PV panel is totally flooded into water). In the majority of the analyzed cooling techniques, direct water flow over the PV panel was established, or in other cases a specific heat exchanger was designed, as an integrated part of the PV panel, to take over sufficient heat from the backside of the PV panel. Besides the convenient magnitude of specific heat rejection, water spray also acts as a self-cleaning element, which can solve one of the major practical problems in the case of PV technology utilization and that is related to dust accumulation on the front surface of a PV panel which can significantly reduce the power output of a PV system.

\section{B. System operation and instrumentation}

The proposed system was operated under four different operating cases:

First case

In the first case, the cooling water pump of the PV panel is turned off. And then the PV panel is operated without cooling techniques. The electrical power and voltage are measured at every electrical load.

\section{Second case}

In the second case, the cooling water pump of the PV panel is switched-on, the front side water pipe line regulating valve is switched-on and the backside water pipe line regulating valve is turned off. The electrical power and voltage are measured at every electrical load.

\section{Third case}

In the third case, the cooling water pump of the PV panel is switched-on, the front side water pipe line regulating valve is turned off and the backside water pipe line regulating valve is switched-on. The electrical power and voltage are measured at every electrical load.

\section{Fourth case}

In the fourth case, the cooling water pump of the PV panel is switched-on, the front side and backside water pipe line regulating valve is switched-on. The electrical power and voltage are measured at every electrical load.

\section{Measurement error analysis}

In this section, we will briefly discuss the expected measurement error for applied measurement equipment and its final influence on the influential measured parameters. For the used measurement equipment in the herein performed experimental analysis, we specified guaranteed measurement error according to the technical sheet data of equipment producers and data are provided in Table 2.

TABLE 2

GUARANTEED MEASUREMENT ERROR FOR THE USED MEASURING EQUIPMENT

\begin{tabular}{|ll|}
\hline Sensor type & Measurement error \\
\hline & \\
Temperature & $\pm 0.3 \%{ }^{\circ} \mathrm{C}$ \\
Flow meter & $\pm 3.0 \%$ \\
Pyranometer & $\pm 0.6 \%$ \\
Voltmeter & $\pm 0.5 \%$ \\
Ammeter & $\pm 1.0 \%$ \\
\hline
\end{tabular}

If we analysed the specified data according to Table 2, the temperature error influence is not a significant one as the guaranteed measurement error is $\pm 0.3 \%$. The expected measurement error in the water flow sensor case is $\pm 3.0 \%$ which also is not a significant influence in relation to the applied water spray flow magnitude. The same situation is also in the case of solar irradiation measurement where guaranteed measurement error is $\pm 0.6 \%$. The same situation is also in the case of voltmeter and ammeter where guaranteed measurement error is $\pm 0.5 \%$ and $\pm 1.0 \%$ respectively. 
Finally, according to the previous elaboration regarding expected measurement error, we can conclude that the guaranteed measurement error impact is generally insignificant.

\section{EXPERIMENTAL RESULTS AND DISCUSSION}

\section{A. General circumstances}

The panel was tested on a geographical location in a Middle east (city of Tanta situated in Egypt). Measurements were provided from 10 am to $14 \mathrm{pm}$. During the series of measurements, the surrounding air temperature ranged from $29^{\circ} \mathrm{C}$ and up to $34{ }^{\circ} \mathrm{C}$. Fig. 5 indicates ambient temperature variation during the measurement period. And also during the series of measurements solar irradiation ranged from 872 $\mathrm{W} / \mathrm{m} 2$ to $1100 \mathrm{~W} / \mathrm{m} 2$. Fig. 6 indicates solar irradiation variation during the measurement period.

During the measurement series, air velocities were under $1.0 \mathrm{~m} / \mathrm{s}$ (the surrounding wind impact was neglectable on the measurements) and inlet water temperature was approximately constant, at around $28{ }^{\circ} \mathrm{C}$ (average measured water inlet temperature from the pipeline).

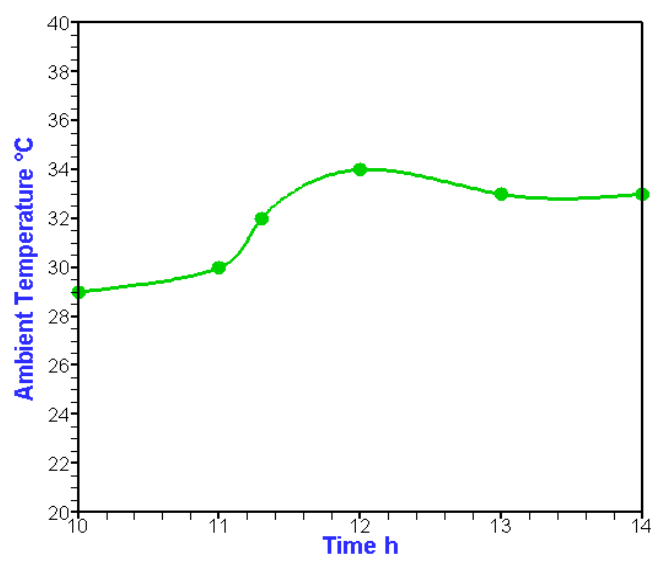

Figure 5. Ambient temperature variation during the measurement period.

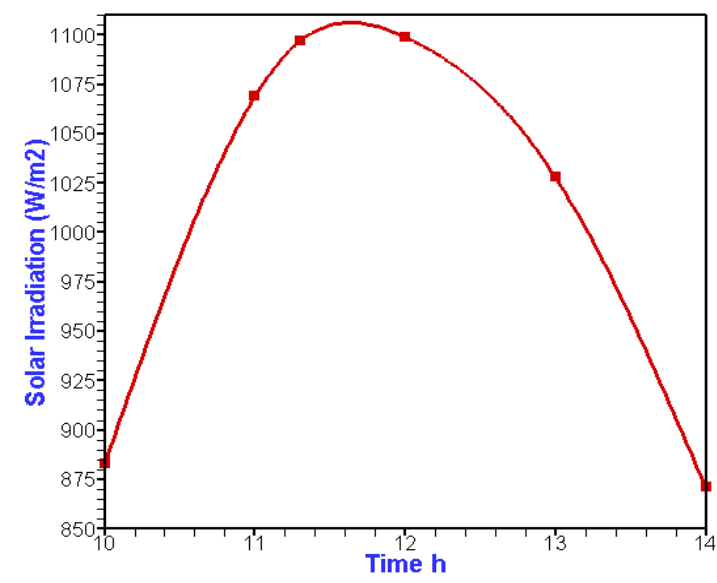

Figure 6. Solar irradiation variation during the measurement period.

\section{B. Water spray cooling technique effect on PV panel temperature reduction}

Achieved temperature reduction between the case of noncooled PV panel and cooled PV panel (in different cooling regimes), was shown in Fig. 7 (the data presented in Fig. 7 are for solar irradiation levels at around $872-1100 \mathrm{~W} / \mathrm{m} 2$, surrounding air temperature at around $29-34{ }^{\circ} \mathrm{C}$ and water spray temperature at around $28^{\circ} \mathrm{C}$ ).

In the case of the non-cooled PV panel, the panel temperature ranged from $50{ }^{\circ} \mathrm{C}$ to $55^{\circ} \mathrm{C}$. On the other side, with the implementation of the water spray cooling technique, it was possible to achieve temperature reduction down to $24{ }^{\circ} \mathrm{C}$ which is a significant decrease. The highest reduction in panel temperature was achieved in the case of simultaneous front and backside PV panel cooling where achieved level temperature reduction, around $24{ }^{\circ} \mathrm{C}$. According to Fig. 7, the difference between front side PV panel cooling and simultaneous cooling of both sides is not a significant one regarding the achieved PV panel temperature decrease.

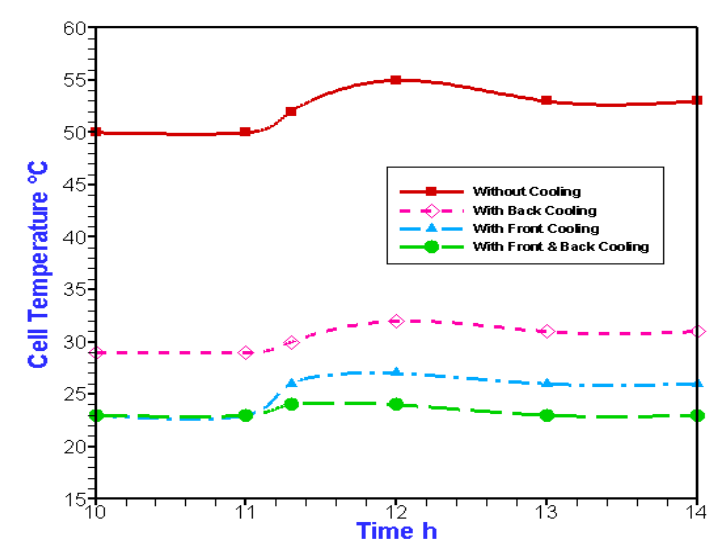

Figure 7. Cell temperature according to different cooling techniques.

C. The cooling effect impact on the electric panel power output and electrical efficiency

Fig. 8 and 9 represents electric power output and electrical efficiency versus time for different applied cooling circumstances through a series of experiments during the measurement period.

The maximal achieved electric power output for the noncooled panel was $75.9 \mathrm{~W}$ in average. In the case of PV panel front side cooling, the maximal achieved electric power output was $87.7 \mathrm{~W}$ in average. In the case of PV panel back side cooling, the maximal achieved electric power output was $86.5 \mathrm{~W}$ in average. And in the case of simultaneous PV panel front and back side cooling, the maximal achieved electric power output was $89.1 \mathrm{~W}$ in average.

The highest increase in electric PV panel power output was achieved in the case of simultaneous PV panel front and backside cooling, where total increase was in the amount of $17.4 \%$ (in comparison with the non-cooled panel). The previous maximal achieved average increase in PV panel electric power output was established for water spray flow which was $225 \mathrm{l} / \mathrm{h}$. 
The mean maximal electrical efficiency for the non-cooled PV panel was $6.91 \%$, and in the case of the panel that was cooled on front side, the maximal achieved mean panel electrical efficiency was $7.98 \%$. Therefore, the overall electrical efficiency increase in the case of the front side cooled was $15.48 \%$ in comparison with average electrical efficiency in the non-cooled PV panel.

In the case of the panel that was cooled on backside, the maximal achieved mean panel electrical efficiency was $7.87 \%$. Therefore, the overall electrical efficiency increase in the case of the backside cooled was $13.89 \%$ in comparison with average electrical efficiency in the non-cooled PV panel.

In the case of the panel that was simultaneously cooled on both sides, the maximal achieved mean panel electrical efficiency was $8.11 \%$. Therefore, the overall electrical efficiency increase in the case of the simultaneously cooled was $17.37 \%$ in comparison with average electrical efficiency in the non-cooled PV panel.

It is clear that the highest efficiency improvement, and also highest mean panel temperature reduction is obtained if both sides of the PV panel are simultaneously cooled with water spray.

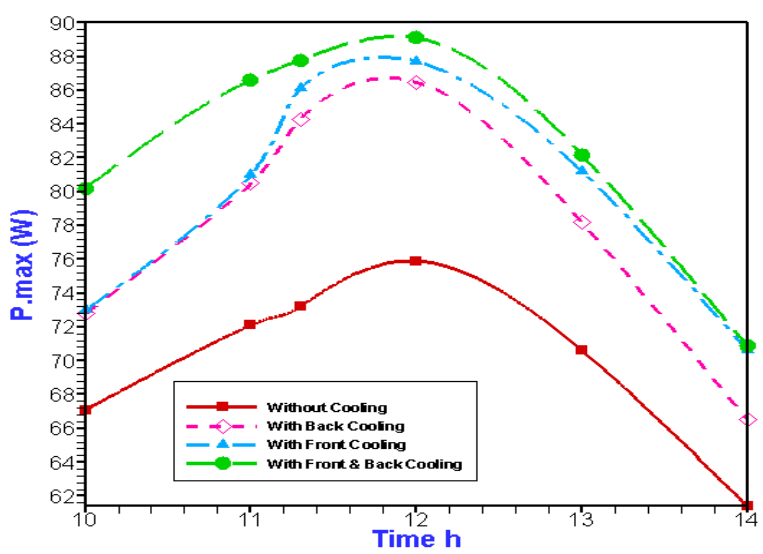

Fig. 8. Electric power output versus time or different applied cooling circumstances.

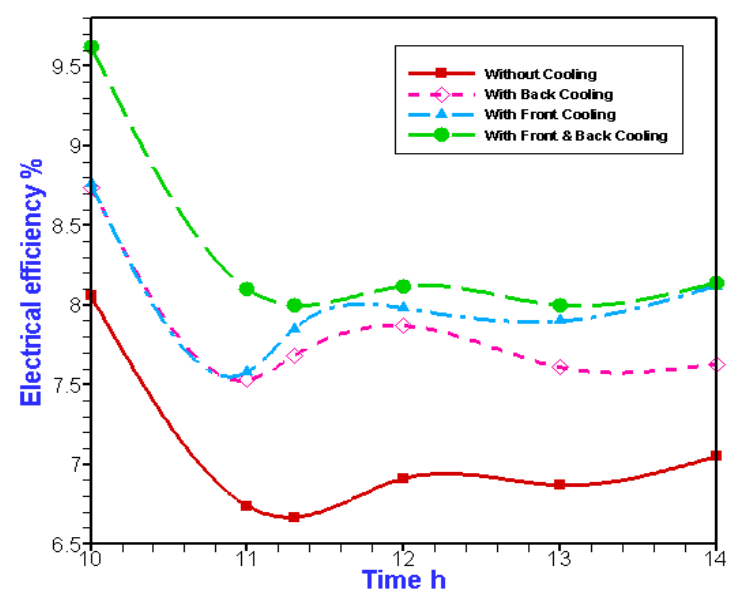

Figure 9. Electric efficiency versus time or different applied cooling circumstances.
It is also important to emphasize that the previously specified values for PV panel electrical efficiency does not include pump work (i.e. equivalent power loss due to the water circulation system).

To conclude, the applied water spray cooling technique has got a favourable impact on panel performance response and its best result is achieved for simultaneous front and backside PV panel cooling (highest panel electrical efficiency increase and highest mean PV panel temperature decrease as well).

\section{Feasibility aspect}

In our case we used water from a pipeline to obtain a water spray with an average pressure of 0.5 bar and 2251/h flow where we measured applied water spray flow with a flow meter for each analysed case. Therefore, regarding the known previously mentioned input parameters, we calculated an equivalent power loss (due to water circulation system, i.e. pumping work), with the assumption that the above specified pressure would be established with a standard circulation pump at an average of 0.7 assumed efficiency.

For the previously mentioned circumstances we calculated equivalent power loss (using standard hydrodynamic relations), it was $4.2 \mathrm{~W}$. The average maximal non-cooled panel power output which was around $75 \mathrm{~W}$.

In case of front side cooling for the PV panel with applied water spray flow of $225 \mathrm{l} / \mathrm{h}$, if we take the maximal achieved power output was $87.7 \mathrm{~W}$, then effective increase in panel power output is $8.5 \mathrm{~W}$ (with $4.2 \mathrm{~W}$ of equivalent power loss included due to the water circulation system), which means that actually, i.e. effective increase in panel power output was around $11.3 \%$ for the previously specified circumstances.

In case of backside cooling for the PV panel with applied water spray flow of $225 \mathrm{l} / \mathrm{h}$, if we take the maximal achieved power output was $86.5 \mathrm{~W}$, then effective increase in panel power output is $7.3 \mathrm{~W}$ (with $4.2 \mathrm{~W}$ of equivalent power loss included due to the water circulation system), which means that actually, i.e. effective increase in panel power output was around $9.7 \%$ for the previously specified circumstances.

In case of simultaneously cooling the PV panel with applied water spray flow of $225 \mathrm{l} / \mathrm{h}$, if we take the maximal achieved power output was $89.1 \mathrm{~W}$, then effective increase in panel power output is $9.9 \mathrm{~W}$ (with $4.2 \mathrm{~W}$ of equivalent power loss included due to the water circulation system), which means that actually, i.e. effective increase in panel power output was around $13.2 \%$ for the previously specified circumstances.

Although, the net power output increase is not a great one, feasibility is proven. Additionally, performance improvement would also be achieved because of the fact that the water spray technique acts as a self-cleaning element for the PV panel (the previous fact is extremely important in practical terms).

\section{CONCLUSIONS}

In this paper, a water spray cooling technique was proposed and experimentally tested on a polycrystalline photovoltaic panel for different cooling circumstances. The best cooling option turned out to be simultaneous cooling of front and backside PV panel surfaces. 
Maximal achieved relative and also effective increase in the panel power output was for the circumstances of simultaneous front and backside PV panel cooling, respectively in the amount of $18.8 \%$ (effective $13.2 \%$ ) and $13.3 \%$ of effective increase in panel electrical efficiency.

Average panel temperature was reduced from $55^{\circ} \mathrm{C}$ up to an average $24^{\circ} \mathrm{C}$, and the lowest possible panel temperature was limited due to constant pipeline water temperature that was around $28^{\circ} \mathrm{C}$.

Finally, according to the gained experimental results, it can be concluded that the proposed water spray cooling technique has got a favourable effect on panel performance and it is also a feasible one. Besides its favourable effect on panel performance, the panel surfaces' self-cleaning effect (on panel performance) is something that should be taken into account long term (which is also an important advantage of the herein proposed cooling technique).

\section{REFERENCES}

[1] Tiwari GN, Mishra RK, Solanki SC. Photovoltaic modules and their applications: a review on thermal modelling. Appl Energy 2011; 88(7):2287-304. July.

[2] Nižetic' S, C`oko D, Marasovic' I. Experimental study on a hybrid energy system with small-and medium-scale applications for mild climates. Energy 2014; 75:379-89.

[3] Nižetic' S, Duic' N, Papadopulos AM, Tina GM, Grubišic'-C`abo F. Energy Efficiency evaluation of a hybrid energy system for building applications in a Mediterranean climate and its feasibility aspect. Energy 2015; 90:1171-9.

[4] Malamaki KND, Demoulias CS. Analytical calculation of the electrical energy losses on fixed-mounted PV plants. IEEE Transact Sustain Energy 2014; 5 (4):1080-9. October.

[5] Mahmoud Y, Xiao W, Zeineldin HH. A simple approach to modeling and simulation of photovoltaic modules. IEEE Transact Sustain Energy 2012; 3 (1):185-6. January.

[6] Alami AH. Effects of evaporative cooling on efficiency of photovoltaic modules. Energy Convers Manage 2014; 77:668-79.

[7] Dorobantu L, Popescu MO. Increasing the efficiency of photovoltaic panels through cooling water film, UPB. Sci Bull, Ser C: Electr Eng 2013; 75(4):223-32.

[8] Abolzadeh M, Ameri M. Improving the effectiveness of a photovoltaic water pumping system by spraying water over the front of photovoltaic cells. Renewable Energy 2009; 34(1):91-6. January.

[9] Bahaidarah H, Subhan A, Gandhidasan P, Rehman S. Performance evaluation of a PV (photovoltaic) module by back surface water cooling for hot climatic conditions. Energy 2013;59:445-53. September.

[10] Fujii M, Yanagihara H, Mitsumoto S, Kikugawa S, Tokoro T, Fukuma M. Improvement of conversion efficiency through water-cooled equipment in photovoltaic system. J Int Council Electr Eng 2013; 3(1):97-101. September.

[11] Du B, Hu E, Kolhe M. Performance analysis of water cooled concentrated photovoltaic (CPV) system. Renew Sustain Energy Rev 2012; 16(9):6732-6. December.

[12] Abdulgafar SA, Omar OS, Yousif KM. Improving the efficiency of polycrystalline solar panel via water immersion method. Int J Innovat Res Sci, Eng Technol 2014; 3(1):8127-32. January.

[13] Smith CJ, Forster PM, Crook R. Global analysis of photovoltaic energy output enhanced by phase change material cooling. Appl Energy 2014; 126(1):21-8.

[14] Rosa-Clot M, Rosa-Clot P, Scandura PF. Submerged photovoltaic solar panel: SP2. Renewable Energy 2010; 35(8):1862-5. August. 